\title{
Interleukin 13 and Interleukin 4 Receptor- $\alpha$ Polymorphisms in Rhinitis and Asthma
}

\author{
Renske W.B. Bottema ${ }^{a} \quad$ Ilja M. Nolte ${ }^{b}$ Timothy D. Howard ${ }^{f}$ \\ Gerard H. Koppelman ${ }^{c}$ Anthony E.J. Dubois ${ }^{c}$ Gea de Meerd, e \\ Marjan Kerkhof $^{b}$ Eugene R. Bleecker ${ }^{f}$ Deborah A. Meyers ${ }^{f}$ Dirkje S. Postma ${ }^{a}$ \\ Departments of a Pulmonology and bepidemiology, University Medical Center, University of Groningen, \\ 'Pediatric Pulmonology and Allergology, Beatrix Children's Hospital, University Medical Center, Groningen, \\ ${ }^{d}$ Municipal Health Service Fryslân, Leeuwarden, eInstitute for Risk Assessment Sciences, Utrecht University, \\ Utrecht, The Netherlands; ${ }^{\mathrm{f} C e n t e r}$ for Human Genomics, Wake Forest University School of Medicine, \\ Winston-Salem, N.C., USA
}

\section{Key Words}

Asthma $\cdot$ Genetics $\cdot I L 13 \cdot I L 4 R \cdot$ Rhinitis $\cdot$ Interaction

\begin{abstract}
Background: Asthma and rhinitis may represent two manifestations of the same airway disease. Genetic research can increase our understanding of their common or distinct pathogenesis. IL13 and IL4R polymorphisms are associated with asthma and show gene-gene interaction in asthma. Their role in rhinitis has not been extensively studied. Methods: Association of IL13 and IL4R polymorphisms in relation to rhinitis, asthma, serum IgE and skin test response was studied in: (1) 188 trios ascertained through a proband with rhinitis who were clinically not affected by asthma; (2) 407 trios with an asthmatic proband, and (3) 118 asthma cases and 102 unrelated healthy controls using family-based association testing, logistic regression, and analysis of variance as appropriate. Gene-gene interaction was evaluated using logistic regression analysis. Results: IL13 C-1111T (rs1800925) was significantly associated with rhinitis and atopic phenotypes in rhinitis trios that were not affected by clinical asthma. IL13 Arg130GIn (rs20541) and G870A (rs1295685) were
\end{abstract}

consistently associated with asthma and serum $\operatorname{lgE}$ in both asthma populations. IL4R Glu375Ala (rs1805011) and Ser411Leu (rs1805013) were associated with asthma in the asthma case-control population. Combining risk genotypes of IL13 Arg130GIn with IL4R Glu375Ala, and IL13 C-1111T with IL4R Ser478Pro yielded increased risks for asthma compared to their separate effects. Conclusion: IL13 polymorphisms were associated with asthma and rhinitis without clinical asthma; thus, these polymorphisms may constitute a common etiologic pathway for their development. In addition, the study replicates a previously reported interaction of $I L 13$ and IL4R polymorphisms in asthma.

Copyright $\odot 2010$ S. Karger AG, Basel

\section{Introduction}

The prevalence of atopic diseases including rhinitis and asthma has been rising worldwide during the last decades. Epidemiological surveys show that rhinitis occurs in $60-85 \%$ of patients with allergic and nonallergic asth$\mathrm{ma}[1,2]$ and constitutes a risk factor for the development of asthma [3]. This has led to the concept that rhinitis and

\section{KARGER}

Fax +41613061234 E-Mail karger@karger.ch www.karger.com (c) 2010 S. Karger AG, Basel

$1018-2438 / 10 / 1533-0259 \$ 26.00 / 0$

Accessible online at:

www.karger.com/iaa
Correspondence to: Prof. Dr. Dirkje S. Postma

Department of Pulmonology

University Medical Center Groningen, University of Groningen

PO Box 196, NL-9700 AD Groningen (The Netherlands)

Tel. +31 50361 3532, Fax +31 503619320 , E-Mail d.s.postma@ int.umcg.nl 
asthma may constitute two manifestations of one airway disease characterized by inflammation of both the upper and lower airways. However, only $10-32 \%$ of patients with rhinitis develop clinical asthma $[2,4]$, which challenges this concept.

Rhinitis and asthma are both complex genetic diseases. Twin and family studies suggest a considerable genetic contribution, with an estimated heritability of $60-70 \%$ for both rhinitis and asthma. Genes important for both diseases as well as disease-specific genes, next to environmental factors, likely play a role in their susceptibility $[5,6]$.

Two genes that are among the most extensively studied in relation to asthma are interleukin 13 (IL13) and the interleukin 4 receptor $\alpha$-chain (IL4R). IL13, a cytokine typically produced during T-helper type 2 cell responses, promotes allergic inflammation by signaling through the IL4R inducing isotype class switch from IgG to IgE production in $\mathrm{B}$ cells. Polymorphisms in genes encoding IL13 and IL4R may therefore constitute a common etiologic pathway in the allergic inflammation observed in asthma and rhinitis.

To determine whether polymorphisms in IL13 and $I L 4 R$ contribute to the development of rhinitis, we studied IL13 and IL4R single-nucleotide polymorphisms (SNPs) in Dutch rhinitis patients who were clinically not affected by asthma and compared our findings with two additional independent Dutch asthma populations. In addition, we set out a replication study of our previously reported [7] interaction of IL13 and IL4R SNPs in asthma.

\section{Patients and Methods}

\section{Study Populations}

Three Dutch Caucasian populations were selected: (1) rhinitis trios, ascertained through 226 patients affected by rhinitis; (2) asthma trios, ascertained through 407 asthma patients, and (3) a case-control population with asthma cases $(\mathrm{n}=118)$ and healthy controls $(n=102)$. Rhinitis and asthma patients were recruited through media appeals and among outpatients in the Departments of Allergology and Pulmonology of the University Medical Center Groningen and local hospitals. The healthy controls were recruited among new employees in an animal laboratory. The local medical ethics committees approved this study, and all participants provided written informed consent.

\section{Ascertainment}

Rhinitis Trios. Rhinitis patients were selected based on a positive answer to the following questions: 'Do you have hay fever?' and 'Do you have a runny or stuffed nose when you are near animals (e.g. dogs, cats, horses), near feathers (e.g. in pillows), or in a dusty part of the house, or when you are near trees, grasses and flowers?' and a self-reported absence of a history of asthma or use of asthma medication. Patients were excluded when affected by nasal polyps, occupational rhinitis or concomitant diseases that could prevent the phenotypic analysis. Following clinical characterization, 38 patients $(17 \%)$ were excluded from further analyses because they had asthma or probable asthma as defined by our asthma algorithm [8]. In this algorithm, airway hyperresponsiveness (AHR), respiratory symptoms, smoking, airway obstruction and bronchodilator response are used to establish an asthma diagnosis. Exclusion was based on AHR combined with: (1) reversible airway obstruction ( $\geq 9 \%$ from baseline; $n=4$ ); or (2) reporting of $\geq 2$ airway symptoms suggestive of asthma (i.e. nocturnal symptoms, dyspnea, cough, wheeze and/or asthma attacks; $\mathrm{n}=$ 26). The remaining patients were excluded because they reported $\geq 2$ airway symptoms suggestive of asthma $(n=2)$, had reversible airway obstruction combined with dyspnea $(n=1)$, or information was incomplete $(\mathrm{n}=5)$.

Asthma Trios. Asthma trios were selected if the patient reported doctor-diagnosed asthma. The diagnosis of asthma was objectively confirmed based on symptoms and clinical tests according to the asthma algorithm [8] (see above).

Asthma Case-Control Population. Individuals in the case-control population participated in studies on the comparison of methacholine and adenosine monophosphate bronchial provocation [9]. Asthma cases were included if they met the following criteria: clinical diagnosis of asthma, AHR, at least one positive skin prick test out of 17 common aeroallergens and reversibility to $\beta_{2}$-agonist $\geq 9 \%$ of predicted $\mathrm{FEV}_{1}$ [9]. Controls participated in a study population of young adults who were mostly asymptomatic [10]. Individuals with AHR who reported $\geq 1$ airway symptom suggestive of asthma (wheeze, cough, dyspnea and/or asthma attacks) were excluded.

\section{Clinical Evaluation}

Before clinical characterization, all participants were asked to stop inhaled corticosteroids at least 14 days before testing, inhaled long-acting $\beta$-agonists and antihistamines $48 \mathrm{~h}$ before testing, and inhaled short-acting $\beta$-agonists and anticholinergics $8 \mathrm{~h}$ before testing. Therapy with oral corticosteroids was continued in 7 patients from the asthma trios.

Rhinitis and Asthma Trios. Rhinitis and asthma trios were characterized using standardized protocols described previously [11]. In brief, a modified version of the British Medical Council questionnaire was applied [12]. AHR to histamine was assessed using a 30 -second inhalation protocol as described by De Vries et al. [13]. A subject was considered hyperresponsive if the provocative concentration of histamine producing a $20 \%$ fall in forced expiratory volume in $1 \mathrm{~s}\left(\mathrm{PC}_{20}\right)$ was $\leq 32 \mathrm{mg} / \mathrm{ml}$. All patients underwent intracutaneous skin testing with 12 common aeroallergens (mixed grasses, tree pollen, mixed weeds, house dust mite, dog, cat, feather mix, guinea pig, Aspergillus fumigatus, Alternaria alternata, Cladosporium herbarum, Penicillum notatum). An individual was regarded skin prick test positive if the mean of the maximum and perpendicular wheal diameter was $\geq 5 \mathrm{~mm}$ in reaction to one or more allergens, provided the control was negative.

Asthma Case-Control Population. In asthma cases, AHR to methacholine was tested with a 2-min tidal breathing method [9] and considered positive if the $\mathrm{PC}_{20}$ methacholine was $<8 \mathrm{mg} / \mathrm{ml}$. Healthy controls were challenged with a breath-actuated dosimeter using a modification of a standardized protocol [10]. AHR for 
Table 1. Characteristics of the rhinitis and asthma trios, asthma patients, and healthy controls

\begin{tabular}{|c|c|c|c|c|}
\hline & \multirow{2}{*}{$\begin{array}{l}\text { Rhinitis trios } \\
\text { probands }\end{array}$} & \multirow{2}{*}{$\begin{array}{l}\text { Asthma trios } \\
\text { probands }\end{array}$} & \multicolumn{2}{|c|}{ Asthma case-control } \\
\hline & & & patients & controls \\
\hline Total number & $188^{1}$ & 407 & 118 & 102 \\
\hline Mean age $\pm S D$, years & $32.8 \pm 8.4$ & $34.3 \pm 8.8$ & $31.8 \pm 8.3$ & $26.9 \pm 5.4$ \\
\hline Male, $\%$ & 45.2 & 36.9 & 65.8 & 44.1 \\
\hline \multicolumn{5}{|l|}{ Mean $\mathrm{FEV}_{1} \%$ predicted $\pm \mathrm{SD}$} \\
\hline AHR, \% positive & $22.4^{2}$ & $91.0^{2}$ & $100.0^{3}$ & $4.0^{4}$ \\
\hline \multicolumn{5}{|l|}{ Serum IgE } \\
\hline Geometric mean, kU/l & 114 & 109 & 237 & 46 \\
\hline Interquartile range, kU/l & $42-266$ & $38-305$ & $114-568$ & $19-122$ \\
\hline$\geq 1$ Positive skin test, $\%$ & 96.2 & 82.9 & 100 & NA \\
\hline
\end{tabular}

these individuals was defined as a cumulative dose of inhaled methacholine causing a $20 \%$ fall in $\mathrm{FEV}_{1} \leq 10 \mu \mathrm{mol}$ [10]. Serum IgE levels in all three populations were measured by means of an enzyme-linked fluorescent assay (Mini Vidas; Biomérieux Inc., Marcy l'Etoile, France).

\section{Molecular Methods}

DNA was isolated from lymphocytes using standard procedures (Puregene kit, Gentra Inc. Minneapolis, Minn., USA). We evaluated three SNPs in IL13, C-1111T (rs1800925), Arg130Gln (rs20541), G870A (rs1295685) and five in IL4R, Ile50Val (rs1805010), Glu375Ala (rs1805011), Ser411Leu (rs1805013), Ser478Pro (rs1805015) and Gln551Arg (rs1801275).

The IL13 polymorphisms were haplotype tagging SNPs selected from the publicly available database of the International HapMap Project [14]. For IL4R, we chose to include SNPs most likely to have a functional impact, based on previous results [7]. Genotyping was performed using the MassARRAY SNP genotyping system (Sequenom Inc., San Diego, Calif., USA).

\section{Statistical Methods}

Genotype data of control individuals were analyzed for deviations from Hardy-Weinberg equilibrium using $\chi^{2}$ statistics (1 degree of freedom)

The phenotypes allergic rhinitis, asthma, AHR, total serum IgE levels and skin prick test response were tested for association with $I L 13$ and $I L 4 R$ genotypes. Total serum IgE was tested as a quantitative variable, after logarithmic transformation to approximate a normal distribution.

In the trios, allele or haplotype transmission distortion from the parents to affected children was analyzed using the familybased association test and its haplotype option (http://biostat. harvard.edu). In the case-control group, association testing was performed using logistic regression and analysis of variance when appropriate. We corrected for the number of tested SNPs ( $n=3$ and 5 for $I L 13$ and $I L 4 R$, respectively) and phenotypes ( $\mathrm{n}=2$ for rhinitis trios and case-controls, and $\mathrm{n}=3$ for asthma trios), by using the Benjamini and Hochberg Step-up False Discovery Rate correction [15]. $\mathrm{p}<0.05$ was considered statistically significant.

Haplotype frequencies in the case-control population were estimated by the expectation-maximization algorithm and used to estimate the separate haplotype frequencies among affected and unaffected individuals. The difference in these frequency distributions was evaluated by a log-likelihood ratio test (in-house software).

Howard et al. [7] previously reported interaction between IL13 C-1111T and IL4R S478P with susceptibility to asthma in our Dutch family study. We similarly tested for gene-gene interaction in asthma cases and controls using logistic regression analyses of combined genotypes. Gene-gene interaction could not be investigated in the trio populations because the study design required transmission disequilibrium testing to combinations of risk genotypes and the numbers of transmitted combined genotypes were considered too small to give reliable estimates.

\section{Results}

A total of 188 rhinitis trios, 407 asthma trios, 118 asthma cases, and 102 healthy controls were evaluated and their clinical characteristics are presented in table 1. A total of 165 rhinitis trios and 295 asthma trios were classical trios, consisting of the proband and both parents.

\section{Genotyping}

The SNPs were in Hardy-Weinberg equilibrium in all three populations. Allele frequencies in each study population are reported in table 2. SNPs Arg130Gln and G870A in IL13 were in almost complete linkage disequi- 
Table 2. SNPs genotyped in $I L 4 R$ and $I L 13$ and their minor allele frequencies in studied populations

\begin{tabular}{lllllll}
\hline $\begin{array}{l}\text { Gene name/ } \\
\text { SNP }\end{array}$ & rs No. & Alleles $^{1}$ & $\begin{array}{l}\text { Rhinitis } \\
\text { pro- } \\
\text { bands }\end{array}$ & $\begin{array}{l}\text { Asthma } \\
\text { pro- } \\
\text { bands }\end{array}$ & $\begin{array}{l}\text { Asth- } \\
\text { ma } \\
\text { cases }\end{array}$ & $\begin{array}{l}\text { Healthy } \\
\text { controls }\end{array}$ \\
\hline IL13 & & & & & & \\
C-1111T12 & rs1800925 & C/T & 0.23 & 0.22 & 0.23 & 0.17 \\
Arg130Gln & rs20541 & G/A & 0.20 & 0.23 & 0.28 & 0.18 \\
G870A & rs1295685 & G/A & 0.20 & 0.23 & 0.27 & 0.18 \\
IL4R & & & & & & \\
Ile50Val & rs1805010 & A/G & 0.45 & 0.51 & 0.46 & 0.46 \\
Glu375Ala & rs1805011 & A/C & 0.13 & 0.12 & 0.08 & 0.17 \\
Ser411Leu & rs1805013 & C/T & 0.05 & 0.05 & 0.07 & 0.03 \\
Ser478Pro & rs1805015 & T/C & 0.19 & 0.17 & 0.16 & 0.19 \\
Gln551Arg & rs1801275 & A/G & 0.22 & 0.22 & 0.24 & 0.27 \\
\hline
\end{tabular}

${ }^{1}$ Major alleles first. ${ }^{2}$ No amino acid change.

librium (LD) and both SNPs showed moderate LD $\left(\mathrm{r}^{2}=\right.$ $0.20-0.33$ ) with C-1111T in all three populations. LD between Ile50Val and other IL4R SNPs was low in all populations. The remaining SNPs within $I L 4 R$ were in strong LD in all populations, except for the SNPs Glu375Ala and Ser411Leu, which did not show LD in the asthma casecontrol study (fig. 1).

\section{Association Analyses}

Rhinitis Trios. IL13 C-1111T was significantly associated with allergic rhinitis and serum $\operatorname{IgE}(\mathrm{p}=0.04$ for both phenotypes, table 3 ). The $\mathrm{T}$ allele was transmitted more frequently than expected. Furthermore, we found a borderline association of IL4R Ile50Val with rhinitis ( $\mathrm{p}=$ 0.06). The 50Ile allele was transmitted more frequently than expected. Family-based haplotype association analyses showed results consistent with SNP analyses. The IL13 haplotype -1111T/130Arg/870G (haplotype frequency $8 \%$ ) was significantly associated with rhinitis and serum IgE ( $\mathrm{p}=0.03$ for both phenotypes). The IL4R haplotype with the wild-type alleles for IL4R SNPs (50Ile/ $375 \mathrm{Glu} / 411 \mathrm{Ser} / 478 \mathrm{Ser} / 551 \mathrm{Gln}$, haplotype frequency $41 \%$ ) was positively associated with rhinitis $(\mathrm{p}=0.04)$.

Asthma Trios. Consistent association of IL13 SNPs Arg130Gln and G870A was found with asthma, AHR, skin test response, and total serum $\operatorname{IgE}(\mathrm{p}<0.05$; table 3$)$. None of the IL4R SNPs showed significant association with asthma, AHR, skin test response or total serum IgE. Analyses of IL13 haplotypes supported the results of SNP analyses. The haplotype with both minor alleles of the associated SNPs Arg130Gln and G870A (-1111C/ $130 \mathrm{Gln} / 870 \mathrm{~A}$, frequency $7 \%$ ) was positively associated with asthma, AHR, skin test response and total serum $\operatorname{IgE}(\mathrm{p}=0.02,0.03,0.02$ and 0.08 , respectively). Haplotypes of IL4R SNPs were not significantly associated with asthma or any atopy phenotype.

A subgroup analysis of allergic (i.e. skin test positive) individuals within the asthma and rhinitis trios showed comparable results. Interestingly, IL4R Glu375Ala and Ser478Pro wild-type alleles were associated with serum $\mathrm{IgE}$ in the allergic asthma trios.

Asthma Case-Control Population. Consistent with the asthma trios, the case-control population showed association of IL13 SNPs Arg130Gln and G870A with asthma and total serum IgE ( $\mathrm{p}<0.05$; table 4$)$. Genotypes with 1 or 2 copies of the $130 \mathrm{Gln}$ and $870 \mathrm{~A}$ alleles were significantly more prevalent in asthmatics than in controls, and were associated with elevated serum IgE levels. The IL4R SNPs Glu375Ala and Ser411Leu were also associated with the presence of asthma $(\mathrm{p}=0.02)$. The homozygous $375 \mathrm{Glu}$ (wild-type) genotype was more prevalent in asthma cases, and thus carriers of the minor alleles showed decreased risks for asthma (table 3). The IL4R haplotype with the wild-type allele 411Ser and minor alleles for the remaining IL4R SNPs (50Val/375Ala/411Ser/551Arg/478 Pro) had a protective effect since the haplotype was significantly less prevalent in asthma cases (3.8\%) than in controls $(9.4 \%, \mathrm{p}=0.03)$. Adjustment for age and gender by using regression analyses did not substantially alter the magnitude ( $<10 \%$ change), the direction or the significance of the association results (data not shown).

\section{Gene-Gene Interaction - Asthma Case-Control Population}

The genotypes IL13 -1111CT/TT and IL4R 478SerSer, previously reported to show gene-gene interaction for asthma in our Dutch family study [7], were not significantly associated with asthma separately, yet their combination showed a trend to association with an increased risk of asthma compared to combined low-risk genotypes -1111CC and 478SerPro/ProPro (odds ratio: 2.3; 95\% confidence interval: $1.0-5.5, p=0.06$; fig. 2 ). In combination, the genotypes that separately showed the strongest evidence for an association with asthma in the case-control population, i.e. IL13 130 Gln carriers and IL4R 375Glu homozygotes, conferred an increased risk of asthma compared to combined low-risk genotypes 130ArgArg and 375AlaAla/GluAla (odds ratio: 4.6; 95\% confidence interval: $1.8-11.9, \mathrm{p}=0.001$; fig. 2). 


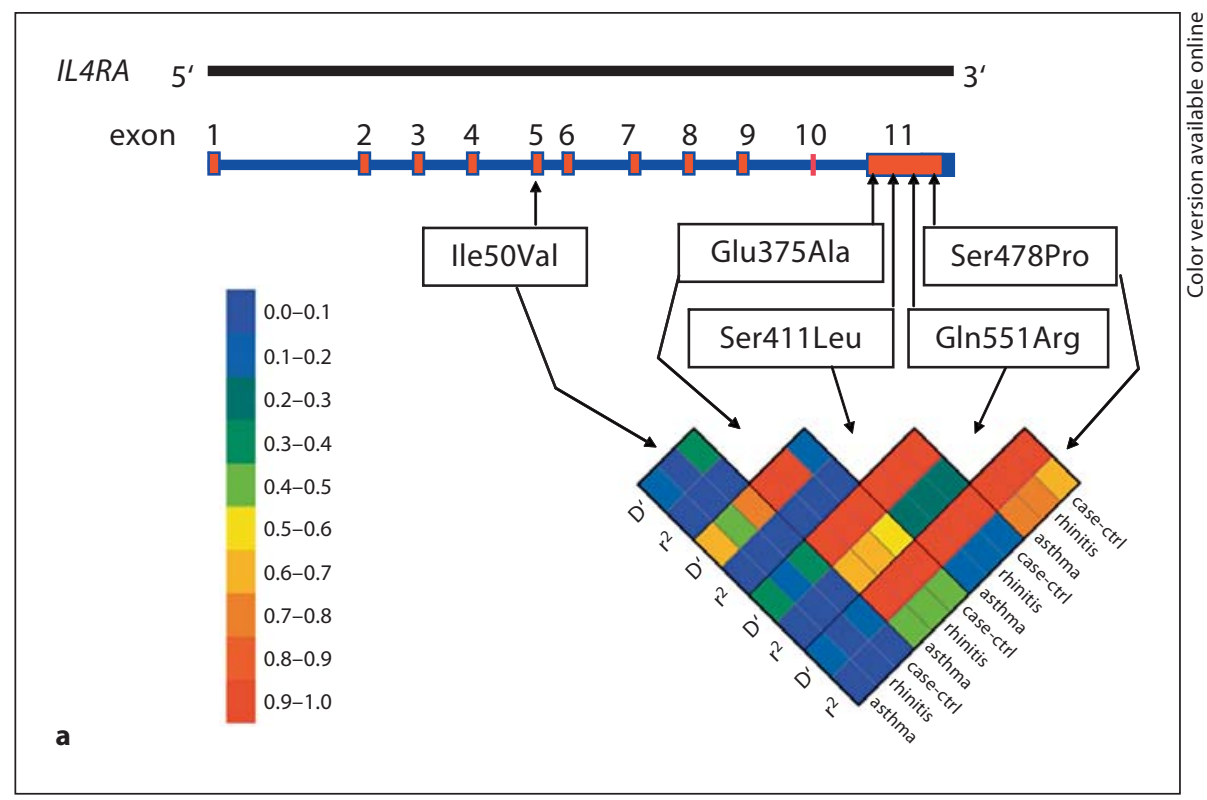

Fig. 1. Position of and LD ( $D^{\prime}$ and $\left.r^{2}\right)$ between SNPs analyzed in IL4R (a) and IL13 (b). $\mathrm{D}^{\prime}$ and $\mathrm{r}^{2}$ between the SNPs within each gene were calculated in each population separately using the expectationmaximization algorithm after first deriving as much phase as possible in the trio populations (in-house software).

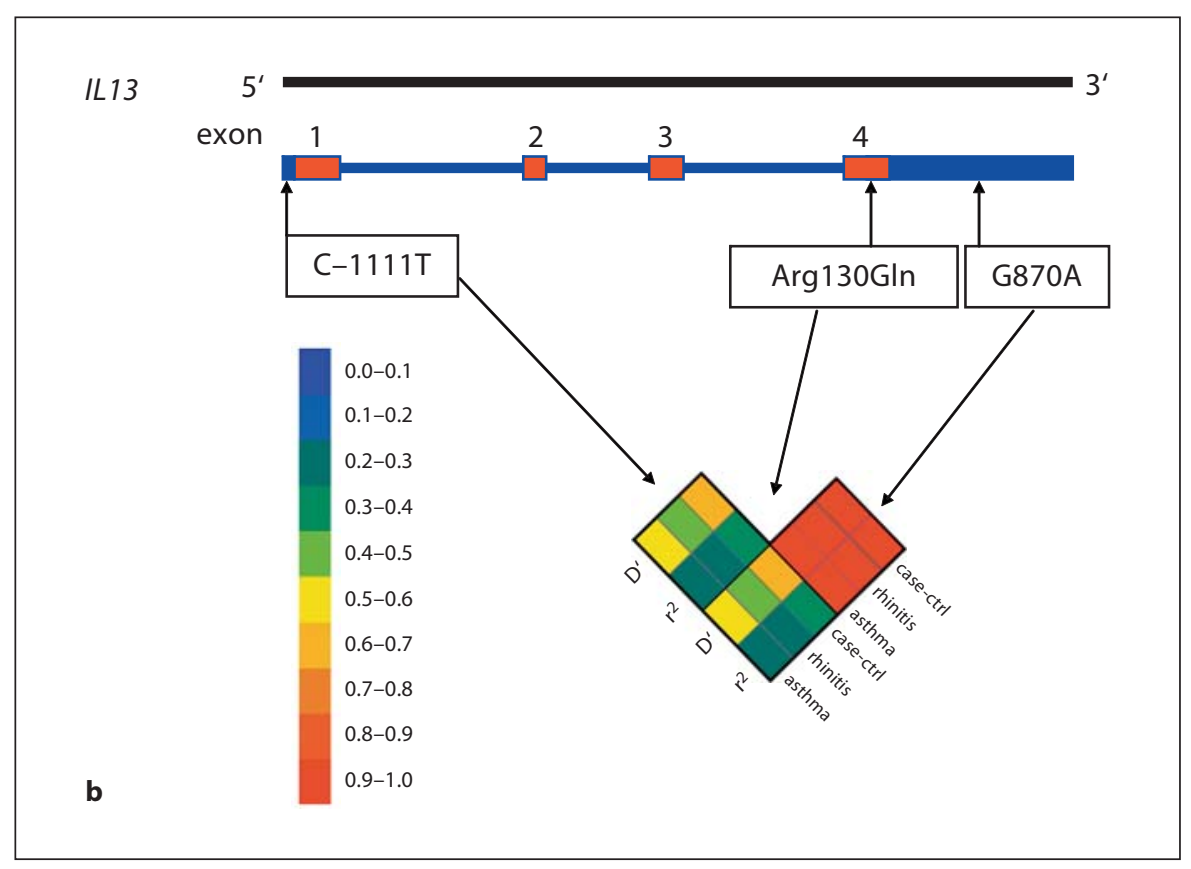

\section{Discussion}

We present the associations of polymorphisms in IL13 and $I L 4 R$ with rhinitis and asthma in a Dutch population. This is the first study that selected a group of rhinitis patients who were not affected by clinical asthma according to extensive clinical evaluation. In these patients, IL13 polymorphisms were associated and IL $4 R$ polymorphisms showed a trend for association with rhinitis and total serum IgE. Additionally, IL13 polymorphisms were also associated with asthma, skin test response, and total serum IgE in two independent asthma populations that were clinically evaluated in a similar standard way. Furthermore, our data confirm an additive influence of IL13 and $I L 4 R$ variants on the susceptibility for asthma, as previously shown by Howard et al. [7].

This study is distinct because the rhinitis patients were subjected to an extensive clinical evaluation and asthma 
Fig. 2. Combinations of genotypes of $I L 4 R$ and IL13 increase the risk of developing asthma. The upper panel shows genotype effects (odds ratios and 95\% confidence intervals by logistic regression) of SNPs. The lower panel shows effects of combinations of genotypes from IL4R and IL13 SNPs.

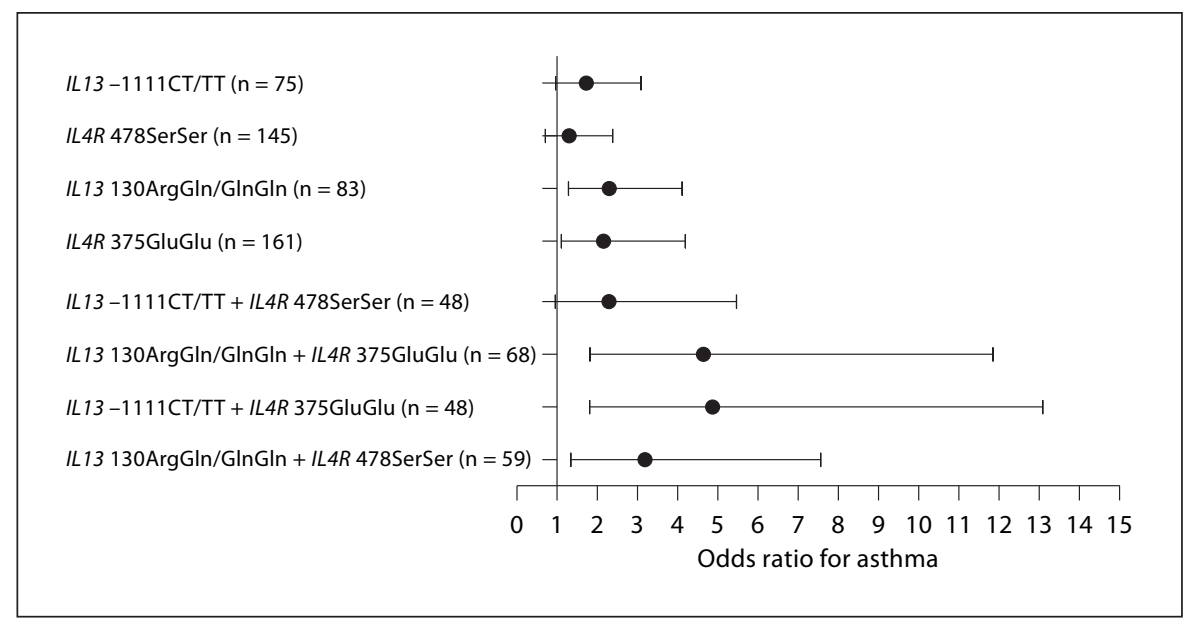

Table 3. Association of $I L 4 R$ and $I L 13$ polymorphisms with rhinitis, asthma and atopy phenotypes, and in the rhinitis and asthma trio populations by using family-based association testing

\begin{tabular}{|c|c|c|c|c|c|c|c|c|c|c|c|c|c|c|c|c|}
\hline \multirow[t]{2}{*}{ SNPs } & \multirow[t]{2}{*}{ Allele } & \multicolumn{3}{|c|}{ Rhinitis } & \multicolumn{3}{|c|}{$\begin{array}{l}\log \operatorname{IgE} \\
\text { in rhinitis trios }\end{array}$} & \multicolumn{3}{|c|}{ Asthma } & \multicolumn{3}{|c|}{$\begin{array}{l}\text { Skin test response } \\
\text { in asthma trios }\end{array}$} & \multicolumn{3}{|c|}{$\begin{array}{l}\log \operatorname{IgE} \\
\text { in asthma trios }\end{array}$} \\
\hline & & $\mathrm{n}^{1}$ & Z score & $\mathrm{p}$ & $\mathrm{n}^{1}$ & $\mathrm{Z}$ score & $\mathrm{p}$ & $\mathrm{n}^{1}$ & Z score & $p$ & $\mathrm{n}^{1}$ & Z score & $p$ & $\mathrm{n}^{1}$ & Z score & $p$ \\
\hline \multicolumn{17}{|l|}{ IL13 } \\
\hline $\mathrm{C}-1111 \mathrm{~T}$ & $\mathrm{~T}$ & 83 & 2.07 & $\begin{array}{c}\mathbf{0 . 0 4} \\
\left(0.24^{2}\right)\end{array}$ & 83 & 2.06 & $\begin{array}{c}\mathbf{0 . 0 4} \\
\left(0.24^{2}\right)\end{array}$ & 144 & 0.38 & 0.71 & 134 & 0.55 & 0.59 & 161 & 1.31 & 0.19 \\
\hline Arg130Gln & Gln & 69 & 0.22 & 0.82 & 69 & 0.48 & 0.63 & 130 & 1.98 & $\begin{array}{c}\mathbf{0 . 0 5} \\
\left(0.08^{2}\right)\end{array}$ & 121 & 2.29 & $\begin{array}{c}\mathbf{0 . 0 2} \\
\left(0.06^{2}\right)\end{array}$ & 151 & 2.11 & $\begin{array}{c}\mathbf{0 . 0 4} \\
\left(0.07^{2}\right)\end{array}$ \\
\hline G870A & A & 80 & 0.52 & 0.60 & 80 & 0.86 & 0.39 & 113 & 2.23 & $\begin{array}{c}\mathbf{0 . 0 3} \\
\left(0.07^{2}\right)\end{array}$ & 107 & 2.71 & $\begin{array}{r}\mathbf{0 . 0 0 7} \\
\left(0.06^{2}\right)\end{array}$ & 133 & 2.66 & $\begin{array}{r}0.008 \\
\left(0.04^{2}\right)\end{array}$ \\
\hline \multicolumn{17}{|l|}{$I L 4 R$} \\
\hline Ile50Val & Val & 125 & -1.87 & 0.06 & 125 & -1.28 & 0.20 & 172 & 0.065 & 0.95 & 164 & 0.72 & 0.47 & 200 & 0.01 & 0.99 \\
\hline Glu375Ala & Ala & 64 & 0.24 & 0.80 & 64 & -0.33 & 0.74 & 89 & -0.69 & 0.49 & 85 & -0.60 & 0.55 & 101 & -0.70 & 0.49 \\
\hline Ser411Leu & Leu & 27 & 0.00 & 1.00 & 27 & -0.14 & 0.89 & 43 & 0.91 & 0.37 & 39 & 0.00 & 1.00 & 48 & 0.94 & 0.35 \\
\hline Ser478Pro & Pro & 81 & 0.41 & 0.68 & 81 & -0.94 & 0.93 & 120 & 0.34 & 0.74 & 115 & 0.60 & 0.55 & 137 & 0.41 & 0.68 \\
\hline Gln551Arg & Arg & 93 & -0.19 & 0.85 & 93 & -0.70 & 0.48 & 143 & 0.76 & 0.45 & 133 & 0.40 & 0.69 & 160 & 0.54 & 0.59 \\
\hline
\end{tabular}

Significant $\mathrm{p}$ values $(\mathrm{p}<0.05)$ are printed in bold type.

${ }^{1}$ Number of informative families.

${ }^{2}$ p value after False Discovery Rate correction; family-based association testing was performed with an additive model and a biallelic test.

was objectively excluded. To explicitly study the relation of IL13 and IL4R SNPs in rhinitis separately from asthma, we had to exclude 38 (17\%) of the 226 patients initially recruited for a self-reported history of rhinitis without asthma. They actually had asthma according to an asthma algorithm that is used to objectively define asthma for genetic research purposes $[7,8,16]$. Our results thus indicate that, due to the high coexistence of asthma and rhinitis, previous genetic studies on rhinitis may have been confounded by the presence of asthma. Notwithstanding this, other studies did report similar findings showing associations of $I L 13$ and $I L 4 R$ polymorphisms with cedar pollinosis [17], nonatopic rhinitis [18], self-reported medical diagnosis of hay fever [19], and allergic rhinitis [20, 21]. These results are strengthened by our findings.

This study on an independent Dutch asthma population shows a similargenetic interaction between the polymorphisms C-1111T in IL13 and Ser478Pro in IL4R and the development of asthma in Caucasian subjects previously shown by Howard et al. [7]. Several studies have addressed a possible genetic interaction between SNPs of the IL13 and IL4R gene, yet with different asthma and al- 
Table 4. Association of $I L 4 R$ and $I L 13$ polymorphisms with asthma, and serum IgE in the asthma case-control study

\begin{tabular}{|c|c|c|c|c|c|c|}
\hline \multirow{2}{*}{$\begin{array}{l}\text { Gene } \\
\text { SNP and genotype }\end{array}$} & \multicolumn{4}{|l|}{ Asthma } & \multicolumn{2}{|l|}{$\log \operatorname{IgE}$} \\
\hline & patients $^{2}$ & controls $^{2}$ & odds ratio ${ }^{3}$ & $\mathrm{p}$ & mean & $\mathrm{p}^{1}$ \\
\hline \multicolumn{7}{|l|}{ IL13 } \\
\hline \multicolumn{7}{|l|}{ C-1111T } \\
\hline $\mathrm{CC}$ & 67 & 65 & 1.0 (reference) & & 1.97 & \\
\hline $\mathrm{CT} / \mathrm{TT}$ & $43 / 5$ & $23 / 4$ & $1.7(1.0-3.1)$ & 0.07 & $2.13 / 2.24$ & 0.10 \\
\hline \multicolumn{7}{|l|}{ Arg130Gln } \\
\hline ArgArg & 57 & 62 & 1.0 (reference) & & 1.95 & \\
\hline GlnArg/GlnGln & $51 / 6$ & $24 / 3$ & $2.3(1.3-4.1)$ & $0.005\left(0.03^{4}\right)$ & $2.15 / 2.37$ & $0.02\left(0.04^{4}\right)$ \\
\hline \multicolumn{7}{|l|}{ G870A } \\
\hline GG & 57 & 62 & 1.0 (reference) & & 1.95 & \\
\hline GA/AA & $52 / 5$ & $25 / 3$ & $2.2(1.2-3.9)$ & $0.007\left(0.02^{4}\right)$ & 2.13 & $0.03\left(0.05^{4}\right)$ \\
\hline \multicolumn{7}{|l|}{$I L 4 R$} \\
\hline \multicolumn{7}{|l|}{ Ile50Val } \\
\hline IleIle & 31 & 18 & 1.0 (reference) & & 2.23 & \\
\hline $\mathrm{IleVal} / \mathrm{ValVal}$ & $58 / 22$ & $22 / 14$ & $0.8(0.4-1.6)$ & 0.48 & $2.10 / 2.14$ & 0.29 \\
\hline \multicolumn{7}{|l|}{ Glu375Ala } \\
\hline GluGlu & 97 & 64 & 1.0 (reference) & & 2.07 & \\
\hline GluAla/AlaAla & $19 / 0$ & $24 / 3$ & $0.5(0.2-0.9)$ & $0.02\left(0.2^{4}\right)$ & $1.91 / 1.99$ & 0.18 \\
\hline \multicolumn{7}{|l|}{ Ser411Leu } \\
\hline SerSer & 100 & 88 & 1.0 (reference) & & 2.03 & \\
\hline SerLeu/LeuLeu & $16 / 0$ & $5 / 0$ & $2.8(1.0-8.0)$ & 0.05 & $2.03 /-$ & 1.00 \\
\hline \multicolumn{7}{|l|}{ Ser478Pro } \\
\hline SerSer & 82 & 63 & 1.0 (reference) & & 2.06 & \\
\hline SerPro/ProPro & $25 / 5$ & $25 / 5$ & $0.8(0.4-1.4)$ & 0.39 & $1.91 / 2.08$ & 0.23 \\
\hline \multicolumn{7}{|l|}{ Gln551Arg } \\
\hline GlnGln & 67 & 51 & 1.0 (reference) & & 2.12 & \\
\hline GlnArg/ArgArg & $38 / 8$ & $30 / 8$ & $0.9(0.5-1.6)$ & 0.78 & $1.90 / 2.05$ & 0.05 \\
\hline $\begin{array}{l}\text { Skin tests were n } \\
{ }^{1} \text { The association } \\
\text { leles were shown in } \\
{ }^{2} \text { Numbers do no } \\
{ }^{3} 95 \% \text { confidence } \\
{ }^{4} \mathrm{p} \text { value after Fa }\end{array}$ & $\begin{array}{l}\text { able. Signifi } \\
\text { sthma best } \\
\text { ison to indi } \\
\text { s add up to } \\
l \text { is shown } \\
\text { overy Rate }\end{array}$ & $\begin{array}{l}\text { ant associat } \\
\text { itted a dom } \\
\text { iduals carry } \\
8 \text { patients a } \\
\text { parenthese } \\
\text { orrection. }\end{array}$ & $\begin{array}{l}\text { ns }(\mathrm{p}<0.05) \text { are } \\
\text { ant genetic mod } \\
\text { ag no copy. } \\
\text { d } 102 \text { controls } d\end{array}$ & $\begin{array}{l}\text { ated in bold ty } \\
\text { nd thus indivic } \\
\text { missing geno }\end{array}$ & $\begin{array}{l}\text { with one o } \\
\text { data. }\end{array}$ & copies of the minor al- \\
\hline
\end{tabular}

lergic phenotypes and variable polymorphisms [22-25], or with other genes $[26,27]$. The odds ratio for asthma in the current study was greater with polymorphisms Arg130Gln and Glu375Ala than with the polymorphisms C-1111T and Ser478Pro, suggesting an additive effect. There was no indication for a multiplicative interaction on a logarithmic scale. However, we interpret this finding with caution since the power to distinguish such an effect is low due to the sample size of our study, resulting in wide confidence intervals as shown in figure 2. However, we think that considering the small sample size, it is even more remarkable to find consistent results with high odds ratios in the same direction as in previous studies. Only one study has addressed the biological effect of combined polymorphisms in IL13 and IL4R [28] and described a synergistic effect of recombinant IL13 Arg130Gln and IL4R Q551R on IL13-induced gene transcription. However, this study does not explain the mechanism underlying this synergism. In order to fully understand the role of variation in these genes in the development of disease, the next challenge will be to elucidate the functionality of these combined SNPs.

Since we have tested three IL13 polymorphisms and five $I L 4 R$ polymorphisms with two phenotypes in the rhinitis and asthma case-control population and three phenotypes in the asthma trio population, one might argue that some of our results reflect type I statistical errors. After correction for multiple testing using False 
Discovery Rate [15], the associations of IL13 SNPs with asthma and serum IgE in the case-control population remained significant ( $\mathrm{p}$ values ranging from 0.02 to 0.05 ). By evaluating whether IL13 and IL4R polymorphisms contribute to rhinitis as well as to asthma, we aimed to test a specific biologically plausible hypothesis and to evaluate the role of these polymorphisms in the Dutch population, and found results in line with other publications. Therefore, we think these are true findings and chose to present our results without correction for multiple comparisons.

The genetic contribution of IL13 and IL4R polymorphisms to the development of both rhinitis and asthma suggests that these polymorphisms influence the development of allergic sensitization and allergic inflammation in both the upper and the lower airways. IL4R Glu375Ala and Ser478Pro were associated with serum IgE in the allergic asthma trios, indicating that these SNPs may represent susceptibility alleles for allergy within asthma patients.

We found an association of rhinitis and asthma with variation in the same genes, but the SNPs and haplotypes were different in rhinitis and asthma. SNPs may have different biological effects depending on cell type or biological milieu. Functional studies have shown that IL13 -1111C/T [29] and Arg130Gln [30, 31] and IL4R Gln551Arg [32, 33], and Ile50Val [34] have functional consequences such as changes in transcription rates, enhanced activity or signaling through the protein, or changes in serum protein levels in diverse cell types.
Some effects are suggested to depend on the biological context, e.g. the $-1111 \mathrm{~T}$ allele is associated with increased IL13 transcription only in a Th2-differentiated cell, not in T-naive cells [29]. Therefore we speculate that development of rhinitis and asthma is induced by variation in IL13, but the SNP or haplotype combinations may determine whether an individual develops rhinitis, asthma, or both in conjunction with environmental and cellular conditions.

In conclusion, our study strongly suggests that IL13 polymorphisms influence the development of rhinitis as well as asthma and their associated allergic phenotypes IgE and skin prick test response. This supports the hypothesis that rhinitis and asthma may be tissue-specific regional manifestations of one disease and shows that IL13 polymorphisms constitute a common etiologic pathway for the development of these conditions.

\section{Acknowledgements}

This work was supported by Netherlands Asthma Foundation grants 3.2.00.37 and AF98.48. R.W.B.B. is supported by a grant from ZonMw, the Netherlands Organisation for Health Research and Development grant No. 912-03-031 and G.H.K. is supported by ZonMw VENI grant No. 91656091 . We thank all participants of the studies. In addition, we acknowledge the work of H. Jongepier and M. ten Berge in recruitment and clinical evaluation of the participants to this study, and the Frisian pulmonologists: J. Nabers, H. Pasma, T.H.E.P. Franssen, P. Eppinga, J.H. Strijbos, W. Evers, and S. Sanwikarja for their help in patient recruitment.

\section{References}

1 Jani AL, Hamilos DL: Current thinking on the relationship between rhinosinusitis and asthma. J Asthma 2005;42:1-7.

2 Bousquet J, Van CP, Khaltaev N: Allergic rhinitis and its impact on asthma. J Allergy Clin Immunol 2001;108(suppl):S147-S334.

-3 Leynaert B, Bousquet J, Neukirch C, Liard R, Neukirch F: Perennial rhinitis: an independent risk factor for asthma in nonatopic subjects: results from the European Community Respiratory Health Survey. J Allergy Clin Immunol 1999; 104:301-304.

-4 Leynaert B, Neukirch F, Demoly P, Bousquet $\mathrm{J}$ : Epidemiologic evidence for asthma and rhinitis comorbidity. J Allergy Clin Immunol 2000;106(suppl):S201-S205

5 Duffy DL, Martin NG, Battistutta D, Hopper JL, Mathews JD: Genetics of asthma and hay fever in Australian twins. Am Rev Respir Dis 1990;142:1351-1358.
6 Dold S, Wjst M, von Mutius E, Reitmeir P, Stiepel E: Genetic risk for asthma, allergic rhinitis, and atopic dermatitis. Arch Dis Child 1992;67:1018-1022.

7 Howard TD, Koppelman GH, Xu J, Zheng SL, Postma DS, Meyers DA, et al: Gene-gene interaction in asthma: IL4RA and IL13 in a Dutch population with asthma. Am J Hum Genet 2002;70:230-236.

8 Panhuysen CI, Bleecker ER, Koeter GH, Meyers DA, Postma DS: Characterization of obstructive airway disease in family members of probands with asthma. An algorithm for the diagnosis of asthma. Am J Respir Crit Care Med 1998;157:1734-1742.

-9 Van Den Berge M, Meijer RJ, Kerstjens HA de Reus DM, Koeter GH, Kauffman HF, et al: $\mathrm{PC}_{20}$ adenosine $5^{\prime}$-monophosphate is more closely associated with airway inflammation in asthma than $\mathrm{PC}_{20}$ methacholine. Am Respir Crit Care Med 2001;163:1546-1550.
10 De Meer G, Heederik D, Postma DS: Bronchial responsiveness to adenosine 5'-monophosphate (AMP) and methacholine differ in their relationship with airway allergy and baseline $\mathrm{FEV}_{1}$. Am J Respir Crit Care Med 2002; 165:327-331

11 Jongepier H, Koppelman GH, Nolte IM, Bruinenberg M, Bleecker ER, Meyers DA et al: Polymorphisms in SPINK5 are not associated with asthma in a Dutch population. J Allergy Clin Immunol 2005;115:486-492.

>12 Panhuysen CI, Bleecker ER, Koeter GH, Meyers DA, Postma DS: Dutch approach to the study of the genetics of asthma. Clin Exp Allergy 1995;25(suppl):35-38.

13 de Vries, Goei JT, Booy-Noord H, Orie NG: Changes during $24 \mathrm{~h}$ in the lung function and histamine hyperreactivity of the bronchial tree in asthmatic and bronchitic patients. Int Arch Allergy Appl Immunol 1962; 20:93-101. 
-14 The International Hapmap Consortium; Altshuler D, Brooks LD, Chakravarti A, Collins FS, Daly MJ, Donnelly P, et al: A haplotype map of the human genome. Nature 2005;437:1299-1320.

15 Garcia LV: Escaping the Bonferroni iron claw in ecological studies. OIKOS 2004;105: 657-663.

16 Meyers DA, Postma DS, Stine OC, Koppelman GH, Ampleford EJ, Jongepier H, et al: Genome screen for asthma and bronchial hyperresponsiveness: interactions with passive smoke exposure. J Allergy Clin Immunol 2005;115:1169-1175.

-17 Nakamura H, Miyagawa K, Ogino K, Endo T, Imai T, Ozasa K, et al: High contribution contrast between the genes of eosinophil peroxidase and IL-4 receptor alpha-chain in Japanese cedar pollinosis. J Allergy Clin Immunol 2003;112:1127-1131.

18 Khoo SK, Zhang G, Backer V, Porsbjerg C, Nepper-Christensen S, Creegan R et al: Associations of a novel IL4RA polymorphism, Ala57Thr, in Greenlander Inuit. J Allergy Clin Immunol 2006;118:627-634.

-19 Woitsch B, Carr D, Stachel D, Schmid I, Weiland SK, Fritzsch C, et al: A comprehensive analysis of interleukin-4 receptor polymorphisms and their association with atopy and IgE regulation in childhood. Int Arch Allergy Immunol 2004;135:319-324.

20 Kim JJ, Min JY, Lee JH: Polymorphisms in the $I L-13$ and $I L-4$ receptor alpha genes and allergic rhinitis. Eur Arch Otorhinolaryngol 2007;264:395-399.

-21 Llanes E, Quiralte J, Lopez E, Sastre B, Chacartegui M, del Pozo V, et al: Analysis of polymorphisms in olive pollen allergy: IL13, IL4RA, IL5 and ADRB2 genes. Int Arch Allergy Immunol 2009; 148:228-238.
22 Chan IH, Leung TF, Tang NL, Li CY, Sung YM, Wong GW, et al: Gene-gene interactions for asthma and plasma total IgE concentration in Chinese children. J Allergy Clin Immunol 2006;117:127-133.

23 Kabesch M, Schedel M, Carr D, Woitsch B, Fritzsch C, Weiland SK, et al: $I L-4 / I L-13$ pathway genetics strongly influence serum IgE levels and childhood asthma. J Allergy Clin Immunol 2006;117:269-274.

24 Liu X, Beaty TH, Deindl P, Huang SK, Lau S, Sommerfeld C, et al: Associations between specific serum IgE response and 6 variants within the genes IL4,IL13, and IL4RA in German children: the German Multicenter Atopy Study. J Allergy Clin Immunol 2004; 113:489-495.

25 Battle NC, Choudhry S, Tsai HJ, Eng C, Kumar G, Beckman KB, et al: Ethnicity-specific gene-gene interaction between $I L-13$ and $I L-4 R \alpha$ among African Americans with asthma. Am J Respir Crit Care Med 2007; 175:881-887

26 Huebner M, Kim DY, Ewart S, Karmaus W, Sadeghnejad A, Arshad SH: Patterns of GATA3 and IL13 gene polymorphisms associated with childhood rhinitis and atopy in a birth cohort. J Allergy Clin Immunol 2008; 121:408-414.

27 Lee SG, Kim BS, Kim JH, Lee SY, Choi SO, Shim JY, et al: Gene-gene interaction between interleukin-4 and interleukin-4 receptor- $\alpha$ in Korean children with asthma. Clin Exp Allergy 2004;34:1202-1208.

$\checkmark 28$ Chen W, Ericksen MB, Levin LS, Khurana Hershey GK: Functional effect of the R110Q IL13 genetic variant alone and in combination with IL $4 R A$ genetic variants. J Allergy Clin Immunol 2004;114:553-560.
29 Cameron L, Webster RB, Strempel JM, Kiesler P, Kabesch M, Ramachandran H, et al: Th2 cell-selective enhancement of human IL13 transcription by IL13-1112C >T, a polymorphism associated with allergic inflammation. J Immunol 2006;177:8633-8642.

30 Vladich FD, Brazille SM, Stern D, Peck ML, Ghittoni R, Vercelli D: IL-13 R130Q, a common variant associated with allergy and asthma, enhances effector mechanisms essential for human allergic inflammation. J Clin Invest 2005;115:747-754.

-31 Arima K, Umeshita-Suyama R, Sakata Y, Akaiwa M, Mao XQ, Enomoto T, et al: Upregulation of IL-13 concentration in vivo by the IL13 variant associated with bronchial asthma. J Allergy Clin Immunol 2002;109: 980-987.

32 Kruse S, Braun S, Deichmann KA: Distinct signal transduction processes by IL- 4 and IL-13 and influences from the Q551R variant of the human IL-4 receptor alpha chain. Respir Res 2002;3:24.

-33 Tachdjian R, Bryce P, Rzymkiewicz D, Truong N, Oettgen H, Chatila T: Enhanced allergic responses and IL-13 induced airway inflammation in mice carrying the human IL-4 receptor alpha chain arginine 576 polymorphism. J Allergy Clin Immunol 2007; 119:523.

34 Yabiku K, Hayashi M, Komiya I, Yamada T, Kinjo Y, Ohshiro Y, et al: Polymorphisms of interleukin (IL)-4 receptor- $\alpha$ and signal transducer and activator of transcription- 6 (Stat6) are associated with increased IL$4 \mathrm{R} \alpha$-Stat 6 signalling in lymphocytes and elevated serum IgE in patients with Graves' disease. Clin Exp Immunol 2007;148:425431 . 